\title{
Should complete stripping operation to the ankle be avoided in the treatment of primary varicose veins due to greater saphenous vein insufficiency? ${ }^{1}$
}

\author{
Deve-se evitar a flebo-extração completa até o tornozelo no tratamento das varizes primárias \\ por insuficiência da veia safena magna?
}

\author{
Hakan Uncu ${ }^{\mathrm{I}}$

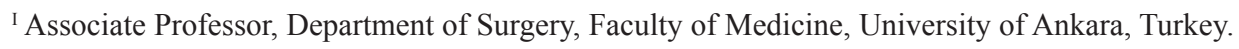

\begin{abstract}
Purpose: The most preferred method for the treatment of primary varicose veins due to greater saphenous vein (GSV) insufficiency is saphenofemoral high ligation and thigh stripping of the GSV, and ambulatory phlebectomy. Stripping is usually ended at the knee level to prevent nerve injury in the calf. However, different surgical modalities may be used depending on the surgeon's choice and experience. Methods: We present the results of complete stripping of the GSV to the ankle and ambulatory phlebectomies performed by a single surgeon. Ninety-six patients (102 limbs) who underwent standardized surgical procedure were participated in this study. Median follow-up time was 3.4 years. Results: All complaints due to varicose veins were resolved in all extremities. Some temporary complications observed were resolved fully during follow-up. Permanent paresthesia which was the most important complication was found only in two patients (2\%). No recurrence was observed. Conclusion: The risk of saphenous nerve injury in the calf should not to be considered a reason to avoid complete stripping of the GSV to the ankle. If it is applied carefully and with appropriate technique, complete stripping still seems to be a good treatment option.
\end{abstract}

Key words: Varicose Veins. Phlebotomy. Saphenous Vein. Venous Insufficiency.

\section{RESUMO}

Objetivo: O método de escolha para o tratamento das varizes primárias devido a insuficiência da veia safena magna (VSM) é a ligagura safenofemoral e a fleboextração em coxa e a flebectomia ambulatorial. A fleboextração é geralmente feita ao nível do joelho para prevenir a lesão neurológica no tornozelo. Diferentes modalidades operatórias, no entanto, podem ser utilizadas dependendo da escolha e da experiência do cirurgião. Métodos: Apresentamos os resultados da fleboextração completa da VSM até o tornozelo e flebectomias ambulatoriais realizadas por um único cirurgião. Noventa e seis pacientes (102 membros) que foram submetidos a procedimento cirúrgico padrão participaram deste estudo. A mediana do tempo de seguimento foi 3,4 anos. Resultados: Todas as queixas devido a varizes foram resolvidas em todos os pacientes. Algumas complicações temporárias observadas foram resolvidas totalmente durante o tempo de seguimento. Parestesia permanente que foi a complicação mais grave ocorreu apenas em dois pacientes (2\%). Não observamos recurrência. Conclusão: O risco da lesão do nervo safeno no tornozelo não deve ser considerada uma razão para evitar-se a fleboextração completa da VSM até o tornozelo. Se é aplicada cuidadosamente e com a técnica apropriada, fleboextração ainda parece ser uma boa opção de tratamento.

Descritores: Varizes. Flebotomia. Veia Safena. Insuficiência Venosa.

${ }^{1}$ Research performed at Department of Surgery, Faculty of Medicine, University of Ankara, Turkey.

\section{Introduction}

Nowadays, one of the commonly encountered health problems is superficial venous insufficiency of the lower extremities and varicose veins. The aim of the treatment is to obtain an acceptable result in terms of cosmetics and relieve the patient's complaints with low complication and recurrence rates. Different surgical interventions and various treatment methods such as compression therapy, foam sclerotherapy or endovenous ablation techniques may be used to treat varicose veins because of superficial venous insufficiency depending on the experience and choice of the physicians. The most preferred treatment method applied still is "saphenofemoral high ligation along with GSV upper segment stripping and ambulatory phlebectomy" in different treatment methods ${ }^{1-3}$. Saphenous vein stripping method has been a standard treatment for a period of more than 40 years. It is accepted to be superior over saphenofemoral ligation and accompanying ambulatory phlebectomy, because reoperation risk is much lower with stripping due to less common recurrences ${ }^{3,4}$. However, stripping method may have negative results such as hemorrhagia, pain, wound infection, discomfort, and long hospitalization periods. Moreover, one of the worst results ensuing is saphenous nerve injury, and it has been observed in more than $23 \%$ of cases. The symptoms of saphenous nerve injury are hypoesthesia, paresthesia or dysesthesia. Because the vein and the nerve are in close proximity at the lower calf, it has been reported 
that ending the stripping above the knee may prevent a possible nerve injury complication. Thus, upper segment stripping performed above the knee, has been the preferred method even in the case of reflux along the whole GSV lenght ${ }^{5-7}$. GSV stripping above the knee may reduce the risk of nerve injury, but it does not eliminate this risk. Restricted stripping of GSV to the knee level may be the reason of developing recurrence of varicose veins in the residual segment below the knee ${ }^{4,8}$.

Complete GSV stripping was preferred in the case of venous insufficiency and venous enlargement in the GSV between the groin and the ankle. We have not encounted any important clinical problem during the application of this surgical treatment method. In present study, the results of complete GSV stripping with the postoperative outcome, morbidity and the incidence of nerve injury were evaluated.

\section{Methods}

The same surgical procedure was applied to the 102 extremities of 96 patients who were diagnosed with reflux in the saphenofemoral region and along the GSV between April 2001 and June 2006 by a single surgeon. All patients had primary varicose veins. The patients were classified as "C2/3, Ep, As2,3" according to the CEAP classification. This is a non-randomised study. Patients who had experienced different type of surgical interventions or the same type of operations performed by different surgeons during this period were not included in this study. Patients with a history of deep vein thrombosis, superficial thrombophlebitis, previous venous surgery, and who had abnormal neurological findings or reflux in the short saphenous vein were also excluded.

The cases were diagnosed by Doppler ultrasound and duplex scanning. All superficial, deep and perforating veins between the groin and the ankle were examined by duplex scanning. All patients had a GSV insufficiency across the whole segment to the ankle. Retrograde flow more than 0.5 seconds in the vein by duplex scanning was considered as venous reflux. Varicose veins clusters detected in the region below the knee during clinical examination were present

The operations were standardized and performed by a single surgeon. The GSV and varicose veins to be operated were mapped on the skin with Doppler ultrasound in the morning at the day of operation. General anesthesia was preferred for the operations. While left lower extremities were operated in 52 patients, right lower extremities were operated in 38 patients, and 6 patients were operated for both extremities. All tributaries of the GSV were dissected through a $2 \mathrm{~cm}$ transverse incision at the saphenofemoral region, then ligated with polyglactin 000 and cut. Again through a small transverse incision applied above the medial malleolus, the distal end of the GSV was dissected attentively. After careful separation of the GSV from the saphenous nerve at the medial malleolous, reusable stripper was applied into the distal end of the GSV and passed proximally to the saphenofemoral junction. Vein was ligated to the stripper from two different points at the location of olive head above the malleolous, and then distal end of GSV was ligated and cut. After the stripper reached to the saphenofemoral junction, proximal end of GSV was divided, ligated, and cut here. The stump of GSV was again closed by a continous polyglactin sutures. GSV stripping was performed in a upward fashion from the ankle towards the groin. When the stripper could not advance throughout the whole vein, a small stripper head was applied between the knee and the ankle. In each case, in order to remove the prominent branch varicosities, phlebectomies were performed with mini incisions. An average of 4.5 varicose vein clusters were excised. When it is necesarry, insufficient perforating veins around the varicose veins were ligated. The bigger incisions inflicted during the operation were closed subcutaneously with polypropylene sutures and the incisions of mini phlebectomies were closed with only strips. Postoperative dressing and elastic bandages were applied from distal to proximal and were not removed for the first 24 hours. Afterwards, compression was applied with elastic compression bandages or graduated compression stockings for 20 days. Prophylaxis with enoxaparin or nadroparin were used in the patients to prevent thromboembolic events.

The patients were asked about the presence of subjective sensory abnormalities such as abnormal or decreased sensation, burning, numbness and tingling after the surgery. Paresthesia as a subjective sensory abnormality was described as pins and needles or a tingling sensation. Dysesthesia was defined as unpleasent distorted sensation from actual sensory stimulation ${ }^{8,9}$.

\section{Results}

The mean age of patients was 39.7 (15-79). Seventy-two of the patients were female and 24 of them were male. While fifty-seven patients had a history of venous problem in the family, 28 had a history of spending long periods of time standing, and 26 patients had a history of hormone usage (Table 1).

TABLE 1 - Patient characteristics

\begin{tabular}{lccc}
\hline & $\begin{array}{c}\text { Patients } \\
(\text { No. } 96)\end{array}$ & Range & $\%$ \\
\hline Age (years) & 39.7 & $(15-79)$ & \\
Weight (kg) & 68.5 & $(50-110)$ & \\
Gender & & & 75 \\
$\quad$ Female & 72 & 25 \\
$\quad$ Male & 24 & \\
Side & & & 39.6 \\
$\quad$ Right & 38 & 54.2 \\
$\quad$ Left & 52 & & \\
$\quad$ Bilateral & 6 & & \\
Duration of symptoms (months) & 67 & & 59.4 \\
Family history & 57 & & 27 \\
Hormon usage & 26 & & \\
Spend long periods of time standing & 28 & & \\
Follow-up (months) & 41 & & \\
\hline
\end{tabular}


The patients presented with various symptoms. The mean duration between the beginning of the symptoms and the presenting date was 5.5 years ( 1 month-35 years). The most common symptom was "pain" determined in 76 patients $(79.1 \%)$.
The second common complaint presented by 36 patients $(37.5 \%)$ was unpleasant appearance and cosmetic concerns. Thirty-four patients (35.4\%) had cramps and 29 (30.2\%) had edema. Presenting symptoms are outlined in Table 2.

TABLE 2 - Presenting symptoms

\begin{tabular}{lcc}
\hline Symptoms & Number of patients (96) & $\%$ \\
\hline Pain & 76 & 79.2 \\
Cosmetic concerns & 36 & 37.5 \\
Cramps & 34 & 35.4 \\
Edema & 29 & 30.2 \\
Tiredness of the legs & 21 & 21.9 \\
Sense of tension, tenseness & 9 & 9.4 \\
Pruritis & 8 & 8.3 \\
Pigmentation & 6 & 6.3 \\
Burning & 5 & 5.2 \\
Unable to step on & 4 & 4.2 \\
Tenderness & 3 & 3.1 \\
Heaviness & 3 & 3.1 \\
\hline
\end{tabular}

The patients were first followed-up on the 20th day postoperatively. Then continuous contact was established with the patients and they were recalled for follow-up controls when required. The median follow-up time was 3.4 years $(5$ months-5.75 years).

Preoperative unpleasant appearances were healed postoperatively in all 102 extremities. In the early postoperative period, 20 (19.6\%) extremities revealed ecchymosis or local small hematoma and $11(10.8 \%)$ extremities displayed edema. While wound infection was not seen in any of the patients, bruising was seen in 12 extremities $(11.8 \%)$ and local inflammation was found in 14 extremities $(13.7 \%)$. These minor complications healed in the follow-up. Thrombosis as one of more important complications was determined in 2 limbs (2\%). Deep vein thromboses were diagnosed by color Doppler examination in the first month postoperatively and they were treated by using low-molecularweight heparin and warfarin for three months. In the early postoperative period, subjective sensory abnormality due to possible saphenous nerve injury was recognized in $12 \mathrm{limbs}$ $(11.8 \%)$. This included numbness or decreased sensation in $7.8 \%$ (8/102 limbs) and paresthesia in 4\% (4/102 limbs). Paresthesia was described by patients as tingling sensation or needles and pins. While numbness and decreased sensation complaints in all patients and two of the paresthesias healed within the follow-up period spontaneously, they proved to be permanent in the extremities of 2 patients (2\%) (Table 3 ). No recurrent varicosities has been observed in any of the patients during the follow-up with objective clinical examination.

TABLE 3 - Complications

\begin{tabular}{lcc}
\hline Complication & Number of extremities (102) & $\%$ \\
\hline Ecchymosis or small hematoma & 20 & 19.6 \\
Edema & 11 & 10.8 \\
Local inflammation & 14 & 13.7 \\
Bruising & 12 & 11.8 \\
Thrombosis & 2 & 2 \\
Sensory abnormality & 12 & 11.8 \\
\hline
\end{tabular}




\section{Discussion}

Genetic predisposition, spending long periods of time standing or sitting, and hormon usage are held responsible for etiology of superficial venous insufficiency and varicose veins for which surgical treatment was discussed here. Symptoms such as pain, tiredness, sense of burning, tenseness, cramp, and itching occur due to increasing pressure in the vein as a result of enlargement and twisting of veins. Least invasive methods with acceptable cosmetic results that can alleviate these presenting symptoms are preferred for treatment ${ }^{10}$. Even less invasive treatment methods have been developed such as endovenous laser, radiofrequency $(\mathrm{RF})$ closure, bipolar coagulating and ultrasound guided foam sclerotherapy, the preferred radical treatment of saphenous insufficiency and varicose veins is still surgery today. High ligation in the saphenofemoral region, multiple phlebectomies may be performed as a surgical alternative. Stripping of GSV may be added in those operations as well. Conventional GSV stripping is associated with morbidity risk such as nerve injury. Besides the risk of nerve injury, as it may be required for future arterial reconstructions, it can not be said that stripping operation is a good choice for treatment. However on the other hand, complete stripping has serious advantage associated with low recurrence rate in the follow-up ${ }^{6,11}$. In a study comparing the GSV stripping from the groin to the ankle and high ligation of the GSV alone, good-to-excellent results of stripping have displayed a high rate of $94 \%$ to $40 \%$, respectively ${ }^{12}$. Only high ligation and phlebectomy procedures are proved to be inefficient, leading to high recurrence and reoperation rates. Currently, the only way to decrease the need for further operation in varicose veins, is routine stripping ${ }^{13}$. GSV stripping in patients suffering from superficial venous insufficiency ensures clear improvements in the quality of life $\mathrm{e}^{8,9,14}$. It also should not be forgotten that when the saphenous vein is already displaying varicoses and incompetency, it will be unstable to use it as a graft.

There is no much discussion about the superiority of GSV stripping with high success and low recurrence rates comparing high ligation alone. Several studies were performed to determine the level of stripping. Nerve injury has been reported at a rate of $23-50 \%$, and because saphenous vein and nerve are localized very closely in the lower calf area, complications due to nerve injury have been thought to be lower if the vein segment across the calf is not removed ${ }^{6,7,11}$. Most of the authors prefer to perform GSV stripping above the knee or just below the knee to prevent nerve injury ${ }^{5,9,11}$. In thigh stripping, where the saphenous vein segment between the groin and the knee have been removed, lower nerve injury rates have been encountered ${ }^{1,13}$. Stripping that ends at the knee-level may decrease risk of paresthesia, but does not totally eliminate $i^{14,15}$. In a study, upper segment stripping and stab avulsions have caused $36.5 \%$ loss of sensation and $8 \%$ paresthesia ${ }^{9}$. Nerve injuries were not only associated with complete GSV stripping. Nerve branches localized close to the vein may be injured during tributary phlebectomy as well as stripping. Moreover, as nerve damage may occur during the dissection in the ankle, dissection at knee-level may cause a nerve damage too. Second most common location of nerve deficit on medial side of calf just below the knee. Thus, methods such as (RF) and endovenous laser ablation have been applied recently in place of stripping. They are only used in procedures above the knee, nontruncal varicosities still require stab avulsion. RF and laser are seen as safe treatment methods. However they also may cause a nerve damage if used below the knee and may induce deep burns related to heat. Thus, if applied appropriately with atraumatic technique carefully, stripping seems to be a good treatment option currently ${ }^{16}$. But the aim of the study never was to compare surgical interventions and the new treatment methods such as laser and RF. The risk of saphenous nerve injury in the calf should not to be considered a reason to avoid complete stripping of the greater saphenous vein to the ankle. In our study, incidence of post-operative sensory abnormality was $11.8 \%$ with little clinical importance. Permanent paresthesia was only $2 \%$ in follow-up period. These two patients with the complaints of paresthesia did not any important discomfort. Morrison had declared similar results with transient nerve deficits. The symptoms consistent with nerve injury after complet GSV stripping affected quality of life in only $2.3 \%$ at long term evaluation ${ }^{14}$. According to a recently published study, complet GSV stripping showed better nerve injury results (19\% at one month) than the nerve injury results of restricted GSV stripping of another study (27\% after surgery $)^{8,17}$. In Flu's study, $99 \%$ of the patients who underwent complet GSV stripping upward resulted in reduction of the complaints of varicose veins with nerve injury rate of $3 \%$ at 3 month follow-up ${ }^{18}$.

In spite of these results, most of vascular surgeons usually prefer thigh stripping between the groin and the knee to prevent nerve damage. Recurrence rates of high ligation and upper segment stripping procedure in the thigh were lower than the isolated high ligation procedure ${ }^{1,4,5}$. However, a recurrence rate of $34 \%$ of upper segment stripping was reported. Reflux occuring with a rate of $29 \%$ in the left distal segment of the saphenous vein was held responsible for the recurrences as well as inappropriate dissection and ligation of tributaries in the saphenofemoral region and neovascularisation arising from saphenofemoral stump or stab avulsion of varicose clusters. The patients may require a reoperation in case of recurrences ${ }^{9,19}$. When restricted GSV stripping is performed, recurrence might be developed due to varicose enlargement of below knee saphenous remnant or its branches. After restricted GSV stripping, recurrence in the distal remnant with the rate of $25 \%$ was reported at the five-year follow-up ${ }^{4}$.

Lower rates of recurrence may be achieved in the application of complete stripping on patients who have whole saphenous insufficiency from the saphenofemoral junction to the ankle named " type I " by well ligating tributaries and the stump in the groin and applying careful dissection and appropriate stripping ${ }^{11,14}$. Nerve injury and related permanent complications do not occur at a severe level as to negatively affect the life of a patient. Thus, by considering those experiences, complete stripping was applied to our patients included in this study and succesful results were achieved. No recurrence was seen during follow-up period and permanent paresthesia rate was fixed only at $2 \%$. This rate might be considered lower than the paresthesia rate of patient groups who have experienced only high ligation and phlebectomy ${ }^{20}$. Various postoperative complications other than paresthesia improved within a short time. Since we believe that in stripping upward, small bulk of the GSV and small olive can pass towards the groin with less nerve damage and can be removed easier, we preferred stripping upward. In our method, no recurrence was observed and the cosmetic results were satisfactory. 


\section{Conclusions}

Various treatment methods may be used in patients presenting with superficial venous insufficiency and varicose veins depending on the localization of venous pathology, patient's features, and surgeon's choice. Varicose vein operations should be performed by well-trained vascular surgeons to prevent complications and recurrence, and to achieve successful results. We can not claim that surgical treatment is superior over the new endovenous treatment methods with this study. But if insufficiency in the whole GSV and saphenous vein deformation across the calf segment with varicose veins are present; complete stripping of the GSV to the ankle with high ligation and phlebectomy also should be the preferred choice due to high success rates and low complication rates. Nerve injury may occur after both complete and partial stripping without any significant difference between them. Most of the symptoms of nerve injury are transient and mild. The possible risk of nerve damage should not be main reason to avoid complete stripping. In presence of clinically appearant varicose veins and duplex verified reflux at the below knee segment of GSV, the right treatment choice may be complet stripping. When permanent complication rates do not significantly differ from those of other treatment methods evaluated along with high success, low recurrence, and low reoperation rates, abandoning complete stripping of the saphenous vein to the ankle is not the right decision currently. According to present study, the question asked in the title of the paper is stil an open question.

\section{References}

1. Kam MH, Tan SG. Results of long saphenous vein stripping. Singapore Med J.2003;44:639-42.

2. Neglen P, Einarsson E, Eklof B. The functional long-term value of different types of treatment for saphenous vein incompetence. J Cardiovasc Surg. 1993;34:295-301.

3. Sarin S, Scurr JH, Coleridge Smith PD. Stripping of the long saphenous vein in the treatment of primary varicose veins. Br J Surg. 1994;81:1455-8. 4. Dwerryhouse S, Davies B, Harradine K, Earnshaw JJ. Stripping the long saphenous vein reduces the rate of reoperation for recurrent varicose veins: five-year results of a randomized trial. J Vasc Surg. 1999;29:589-92.
5. Nishibe T, Nishibe M, Kudo F, Flores J, Miyazaki K, Yasuda K. Stripping operation with preservation of the calf saphenous veins for primary varicose veins: hemodynamic evaluation. J Cardiovasc Surg. 2003;11:341-5.

6. Munn SR, Morton JB, Macbeth WAAG, McLeish AR. To strip or not to strip the long saphenous vein? A varicose vein trial. Br J Surg. 1981;68:426-8. 7. Negus D. Should the incompetent saphenous vein be stripped to the ankle. Phlebology. 1986;1:33-6.

8. Kostas TT, Ioannou CV, Veligrantakis M, Pagonidis C, Katsamouris AN. The appropriate length of great saphenous vein stripping should be based on the extent of reflux and not on the intent to avoid saphenous nerve injury. J Vasc Surg. 2007;46:1234-41.

9. Subramonia S, Lees T. Sensory abnormalities and bruising after long saphenous vein stripping: impact on short-term quality of life. J Vasc Surg. 2005;42:510-4.

10. Teruya TH, Ballard JL. New approaches for the treatment of varicose veins. Surg Clin N Am. 2004;84:1397-417.

11. Koyano K, Sakaguchi S. Selective stripping operation based on Doppler ultrasonic findings for primary varicose veins of the lower extremities. Surgery. 1988;103:615-9.

12. Lofgren EP, Lofgren KA. Recurrence of varicose veins after the stripping operation. Arch Surg. 2001;102:111-4.

13. Winterborn RJ, Foy C, Earnshaw J. Causes of varicose vein recurrence: late results of a randomized controlled trial of stripping the long saphenous vein. J Vasc Surg. 2004;40:634-9.

14. Morrison C, Dalsing MC. Signs and symptoms of saphenous nerve injury after greater saphenous vein stripping: prevalance, severity, and relevance for modern practice. J Vasc Surg. 2003;38:886-90.

15. Holme JB, Skajaa K, Holme K. Incidence of lesions of the saphenous nerve after partial or complete stripping of the long saphenous vein. Acta Chir Scand. 1990;156:145-8.

16. Neglen P. Long saphenous stripping is favored in treating varicose veins. Dermatol Surg. 2001;27:901-2.

17. Wood JJ, Chant H, Laugharne M, Chant T, Mitchell DC. A prospective study of cutaneous nerve injury following long saphenous vein surgery. Eur J Vasc Endovasc Surg. 2005;30:654-8.

18. Flu HC, Breslau PJ, Hamming JF, Lardenoye JW. A prospective study of incidence of saphenous nerve injury after total great saphenous vein stripping. Dermatol Surg. 2008;34:1333-9.

19. Jones L, Braithwaite BD, Selwyn D, Cooke S, Earnshaw JJ. Neovascularisation is the principal cause of varicose vein recurrence: results of a randomised trial of stripping the long saphenous vein. Eur J Vasc Endovasc Surg. 1996;12:442-5.

20. Sarin S, Scurr JH, Coleridge Smith PD. Assessment of stripping the long saphenous vein in the treatment of primary varicose veins. Br J Surg. 1992;79:889-93.

\section{Correspondence:}

Hakan Uncu, MD.

Associate Professor of Surgery

Ankara Üniversitesi Tip Fakültesi

Genel Cerrahi Anabilim Dali

Cebeci

06590 Ankara, Turkey

Fax: (90.312)5083348

drhakanuncu@yahoo.com

Conflict of interest: none

Financial source: none

drhakanuncu@yahoo.com

Received: March 23, 2009

Review: May 19, 2009

Accepted: June 25, 2009

\section{How to cite this article}

Uncu H. Should complete stripping operation to the ankle be avoided in the treatment of primary varicose veins due to greater saphenous vein insufficiency? Acta Cir Bras. [serial on the Internet] 2009 Sept-Oct;24(5). Available from URL: http://www.scielo.br/acb 